\title{
Update to Perinatal-Neonatal Management of COVID-19 Guidelines
}

\author{
Sindhu Sivanandan, ${ }^{1}$ Deepak Chawla, ${ }^{2}$ Praveen Kumar ${ }^{3}$ For the National Neonatology Forum of India \\ (NNF), FEDERATION OF OBSTETRIC AND GYNAECOLOGICAL SOCIETIES OF INDIA (FOGSI), AND INDIAN ACADEMY OF \\ Pediatrics (IAP) \\ From ${ }^{1}$ Department of Neonatology, JIPMER, Puducherry; ${ }^{2}$ Department of Neonatology GMCH, Chandigarh; ${ }^{3}$ Department of \\ Pediatrics, PGIMER, Chandigarh. \\ Correspondence to:Dr Praveen Kumar, Professor, Department of Pediatrics,PGIMER, Chandigarh.drpkumarpgi@gmail.com
}

The guidelines for diagnosing and managing perinatal SARS-CoV-2 infection for the Indian context were last updated in May 2020. Newer evidence, the evolution of the pandemic, and its significant impact on mother-infant dyads led us to review and revise the guideline. This article summarizes the salient changes inthe perinatal-neonatal management of COVID-19.

Keywords: Newborn, Pregnancy, SARS-CoV-2.

Published online: November 22, 2021; PII: S097475591600374

I ndia witnessed the second surge of COVID-19 in March 2021 due to the SARS-CoV-2 double-mutant strain B.1.617 [1]. During this period, the test positivity rate was more than $20 \%$, and pregnant women were noted to experience severe illness [2].The initial guidelines on diagnosis and management of perinatal SARS-CoV-2 infection in India were published in April 2020 [3] and updated in May 2020. The guideline development group (GDG) updated the systematic review to evaluate new evidence and used the GRADE methodology to develop recommendations [4]. We, herein, summarize the updates on managing pregnant women and neonates exposed to COVID-19. Readers may refer to the version 3 of the complete recommendations for more details [4].

\section{Recommendations for the Management of COVID- 19 in Pregnancy and Labor}

COVID-19 in pregnancy is associated with an increased risk of severe disease and pregnancy-related compli-cations such as preeclampsia/eclampsia, gestational diabetes, and thrombosis [5,6]. Pregnant women with COVID-19 have a two-fold higher risk of needing intensive care, mechanical ventilation, extracorporeal membrane oxygenation, and higher mortality [7]. Increased maternal age, obesity, preexisting comorbidity, chronic hyper-tension, diabetes, and preeclampsia are associated with severe illness [7]. The risk of stillbirth, intrauterine growth restriction, and preterm birth is increased twofold. The updated recommendations are listed below:

i) The updated COVID-19 testing strategy for pregnant women (Table I) is based on the Indian Council of Medical Research (ICMR) recommendations [2]. ii) The decision to manage a COVID-19 positive pregnant woman at home or in a health facility depends on obstetric risk factors, comorbidities, the severity of COVID-19 illness, and social conditions. Women with obstetric complications, moderate or severe COVID-19 illness, unsuitable social conditions, and situations where telemonitoring is difficult should be admitted to a health facility. Home quarantine is cost-effective, but tele-consultation services are mandatory for monitoring.

iii) Maternity care services and other specialty services are available at Dedicated COVID Health Centers (DCHC) and Dedicated COVID Hospitals (DCH). All suspected or confirmed COVID-19 pregnant women should deliver at DCHC or DCH as per disease severity and availability of obstetric and neonatal services.

iv) The use of steroids in pregnant women with COVID-19 depends on fetal and maternal indications (Table II). Dexamethasone given for ten days or until discharge to hospitalized patients with moderate to severe COVID-19 on oxygen or respiratory support has been shown to reduce mortality by $30 \%$ [8]. For fetal lung maturity, dexamethasone is given $6 \mathrm{mg}$ IM every 12 hours for four doses. When used solely for maternal indications, alternate steroids (methylprednisolone, prednisolone, or hydrocortisone) can be considered based on availability, cost, and individual preference $[9,10]$.

v) In asymptomatic/mild disease, pregnancy should be continued until term or based on obstetric indications. The mode of delivery should be guided by obstetric indications, cardiorespiratory stability, and oxygenation. COVID-19 itself is not an indication to terminate a 
Table I Updated Recommendations for COVID-19 Testing Among Pregnant Women

\begin{tabular}{llll}
\hline Testing situation & $\begin{array}{l}\text { Surveillance in containment } \\
\text { zones and screening at } \\
\text { points of entry }\end{array}$ & $\begin{array}{l}\text { Surveillance in non- } \\
\text { containment zones }\end{array}$ & Hospital Settings \\
\hline $\begin{array}{l}\text { Indications for } \\
\text { testing }\end{array}$ & $\begin{array}{l}\text { Test irrespective of } \\
\text { symptoms }\end{array}$ & $\begin{array}{l}\text { Test if a history of travel to } \\
\text { a high-risk area in the last 2 wk } \\
\text { Symptomatic }\end{array}$ & $\begin{array}{l}\text { All pregnant women in or } \\
\text { near labor and hospitalized } \\
\text { for delivery }\end{array}$ \\
$\begin{array}{l}\text { Direct contact with a laboratory- } \\
\text { confirmed case }\end{array}$ & RT-PCR or TrueNat or & RT-PCR or TrueNat or \\
order of priority & RAT & CBNAAT & CBNAT \\
\hline
\end{tabular}

Note: No emergency procedure (including deliveries) should be delayed for lack of test. Pregnant women should not be referred for lack of testing facilities. All arrangements should be made to collect and transfer samples to testing facilities.

Table II Recommendations for the Use of Steroids in Pregnant Women With COVID-19

\begin{tabular}{|c|c|c|c|}
\hline \multicolumn{2}{|c|}{ Indication for steroids } & \multirow[t]{2}{*}{ Setting } & \multirow[t]{2}{*}{ Dose schedule } \\
\hline $\begin{array}{l}\text { Fetal lung } \\
\text { maturation }\end{array}$ & $\begin{array}{l}\text { Maternal } \\
\text { COVID-19illness }\end{array}$ & & \\
\hline Yes & No & All settings & $\begin{array}{l}\text { Dexamethasone } 6 \mathrm{mg} \text { IM every } 12 \text { hours for four doses, } \\
\text { irrespective of maternal COVID- } 19 \text { status. }\end{array}$ \\
\hline \multirow[t]{2}{*}{ No } & Yes & Resource limited & $\begin{array}{l}\text { Dexamethasone } 6 \mathrm{mg} / \text { day } \mathrm{PO} / \mathrm{IV} \text { for ten days or until } \\
\text { discharge, whichever is earlier. }\end{array}$ \\
\hline & & $\begin{array}{l}\text { Resourceful (available, } \\
\text { affordable, and maternal } \\
\text { preference for dexamethasone } \\
\text { alternatives) }\end{array}$ & $\begin{array}{l}\text { Methylprednisolone or Prednisolone or Hydrocortisone } \\
\text { in equivalent doses for ten days or until discharge, whichever } \\
\text { is earlier. }\end{array}$ \\
\hline \multirow[t]{2}{*}{ Yes } & Yes & Resource limited & $\begin{array}{l}\text { Dexamethasone } 6 \mathrm{mg} \text { IM every } 12 \text { hourly for four doses } \\
\text { ( } 2 \text { days) followed by } 6 \mathrm{mg} / \text { day PO/IV for eight more days or } \\
\text { until discharge, whichever is earlier. }\end{array}$ \\
\hline & & $\begin{array}{l}\text { Resourceful (available, } \\
\text { affordable, and maternal } \\
\text { preference for dexamethasone } \\
\text { alternatives) }\end{array}$ & $\begin{array}{l}\text { Dexamethasone } 6 \mathrm{mg} \text { IM every } 12 \text { hours for four doses } \\
\text { ( } 2 \text { days) followed by Methylprednisolone or Prednisolone } \\
\text { or Hydrocortisone in equivalent doses for eight more days } \\
\text { or until discharge, whichever is earlier. }\end{array}$ \\
\hline
\end{tabular}

pregnancy or perform a caesarean section. However, a caesarean section may be indicated to manage respiratory failure in critically ill pregnant women with refractory hypoxemia.

vi) Symptomatic pregnant women with fever $>39^{\circ} \mathrm{C}$ despite the use of antipyretics, moderate or severe COVID-19 illness, or comorbid conditions (poorly controlled hypertension or diabetes, preeclampsia, pre-labor rupture of membranes, bleeding per vaginum) should be admitted to a DCH having an intensive care unit with multidisciplinary support. Management of COVID-19 illness in pregnancy is provided in Box I.

vii) COVID-19 vaccines can be offered at any gestational age in pregnancy, but the second dose should preferably be completed before the third trimester. Physicians should inform pregnant and lactating women of the risks of
COVID-19, the benefits of vaccination in the local epidemiological context, and limited safety data and assist them in the informed decision-making process.

\section{Recommendations for the Management of Neonates With COVID-19}

Among neonates born to COVID-19 positive mothers, the proportion with a positive test ranges from $0.5 \%$ to $13 \%$ (median 2\%) [5,6]. The NNF COVID-19 registry observed a $10 \%$ positivity rate [11]. This variability is explained by the variation in testing policy and the population profile.

i) Neonatal resuscitation should follow standard guidelines, and providers should use appropriate personal protective equipment (PPE). Delayed cord clamping and skin-to-skin care at birth should be practiced for all stable neonates born to COVID-19 positive women. The risk of postnatal COVID-19 


\section{Box I Updated Management of COVID-19 During Pregnancy and Labor}

Asymptomatic or Mild illness

Home isolation with active surveillance by telemonitoring or admission to a health facility based on obstetric risk factors, comorbidities, and social conditions

Indications for hospitalization: Worsening dyspnea, unremitting fever $>39^{\circ} \mathrm{C}$ despite antipyretics, inability to tolerate oral hydration and medications, persistent pleuritic chest pain, confusion, or obstetric complications.

Home care comprises supportive measures, e.g., hydration, adequate rest, and frequent ambulation with increased activity as tolerated.

The use of ivermectin or doxycycline is contraindicated.

Vitamin C, Vitamin D, and Zinc are not recommended for the treatment of COVID-19.

Moderate or severe illness

Admit to a dedicated COVID hospital with a high dependency unit or intensive care unit

Oxygen therapy: Maintain SpO2>94\%. Awake-prone positioning if feasible and acceptable.

Remdesivir: Remdesivir should not be withheld from pregnant patients if indicated (patients requiring oxygen therapy, especially early in the disease course). Guidelines issued by the government about rationale use of remdesivir should be followed

Venous thromboembolism prophylaxis: All pregnant women with COVID-19 should be assessed for the risk of venous thromboprophylaxis and prescribed prophylactic anticoagulation with low molecular weight heparin/ unfractionated heparin (e.g., enoxaparin $40 \mathrm{mg}$ once daily or dalteparin $5000 \mathrm{IU}$ once daily) and continued for ten days following hospital discharge unless there is a contraindication.

Tocilizumab: The use of tocilizumab (interleukin-6 receptor antagonist) should be considered for women meeting the criteria, i.e., hypoxia and systemic inflammation. During pregnancy, decisions about tocilizumab administration must include shared decision-making between the pregnant woman, family, and the healthcare provider.

Monoclonal antibody: Monoclonal antibody therapy such as bamlanivimab-etesevimab and the casirivimab-imdevimab combination should not be withheld from pregnant patients if they qualify for its use (non-hospitalized patients with mild to moderate COVID-19 who are at high risk for progressing to severe disease and hospitalization) after a discussion of the potential benefits and risks.

Convalescent plasma therapy: There is no role for convalescent plasma therapy

transmission can be reduced if mothers wear a triple layer mask and strictly adhere to respiratory etiquettes. The use of filters with T-piece/bag-mask devices and aerosol boxes forintubation is not recommended.

ii) Mother-infant dyads should room-in, and exclusive breastfeeding should be encouraged regardless of maternal COVID-19 status. When direct feeding or rooming-in is not feasible, the mother's expressed milk should be provided.

iii) Kangaroo care is recommended for low birthweight neonates regardless of the COVID-19 status of the mother or neonate.

iv) Symptomatic neonates with suspected COVID-19 should be isolated in a COVID designated area. The suspect and confirmed COVID-19 cases should be segregated.

v) All forms of respiratory support are at risk of generating aerosols, and healthcare providers must wear appropriate PPE. The area providing respiratory support should preferably be a negative air pressure area.

$v i$ The updated testing strategy for various scenarios is provided in Table III. Serologic testing (total, IgM, or
IgG antibody levels) is not recommended to diagnose COVID-19 in neonates.

vii) Neonates with asymptomatic or mild COVID-19 require no additional routine laboratory tests. Those with moderate or severe COVID-19 illness should undergo relevant biochemical, hematologic, and coagulation tests to assess the complications and rule out alternate diagnoses. Neonates with severe COVID-19 requiring mechanical ventilation, in whom alternate causes such as neonatal sepsis have been ruled out, may benefit from dexamethasone, $0.15 \mathrm{mg} / \mathrm{kg}$ once daily for 5-14 days. Specific anti-COVID-19 treatment (remdesivir, lopinavir/ritonavir, chloroquine/ hydroxychloroquine, ivermectin, or interferon) and adjuvant therapies (intravenous gamma globulin) are not recommended.

viii) Stable mother-infant dyads may be discharged from the health facility after 24-48 hours of delivery if discharge criteria are met, and birth vaccination is completed. All COVID exposed neonates should be followed up for at least 14 days and preferably till 28 days of life.

ix) The GDG recommends using the WHO case definition for MIS in children for the neonatal age. A 2-tiered approach - proposed by the American College of 
Table III Updated Recommendations for SARS-CoV-2 Testing Among Neonates

\begin{tabular}{|c|c|c|}
\hline \multirow[t]{2}{*}{ Scenario } & \multicolumn{2}{|l|}{ Recommendations } \\
\hline & Timing of first test & Repeat testing \\
\hline $\begin{array}{l}\text { Suspected perinatal transmission: } \\
\text { (Mother with COVID-19 detected within } \\
14 \text { days before or within } 2 \text { days after } \\
\text { delivery) }\end{array}$ & $\begin{array}{l}\text { Between } 24-48 \text { hours of age. Rooming- } \\
\text { in should not be postponed if testing is } \\
\text { delayed. } \\
\text { In case of early discharge, take a pre- } \\
\text { discharge sample. }\end{array}$ & $\begin{array}{l}\text { A repeat test is desirable at } 5-7 \text { days of } \\
\text { age (or earlier if the neonate becomes } \\
\text { symptomatic). } \\
\text { Repeat testing can help to prevent } \\
\text { transmission from the neonate (who is } \\
\text { likely to be asymptomatic even if } \\
\text { infected) to other family members. }\end{array}$ \\
\hline $\begin{array}{l}\text { History of exposure to personnel with } \\
\text { COVID-19 (including mother or family } \\
\text { member or healthcare provider) }\end{array}$ & $\begin{array}{l}\text { Asymptomatic high-risk contacts to be } \\
\text { tested once between day } 5 \text { and day } 10 \text { of } \\
\text { coming into contact (if symptomatic, see } \\
\text { below) }\end{array}$ & - \\
\hline $\begin{array}{l}\text { Symptomatic neonates (irrespective of } \\
\text { history of exposure) with onset at or } \\
\text { beyond } 48 \text { hours of life and presenting } \\
\text { with acute respiratory (respiratory } \\
\text { distress or apnea with or without cough, } \\
\text { with or without fever) or sepsis-like } \\
\text { illness (fever, lethargy, poor feeding, } \\
\text { seizures or diarrhea). }\end{array}$ & $\begin{array}{l}\text { At the time of the first evaluation. } \\
\text { Immediate RAT, if available, can help } \\
\text { decide the transfer of the neonate to an } \\
\text { appropriate area. }\end{array}$ & $\begin{array}{l}\text { If negative, repeat the test in } 24-48 \mathrm{~h} \text { if } \\
\text { the index of suspicion is high. } \\
\text { If the neonate requires ongoing hospital } \\
\text { care because of prematurity and its } \\
\text { complications, documentation of } \\
\text { negative RT-PCR is desirable before } \\
\text { shifting to a non-COVID area. }\end{array}$ \\
\hline
\end{tabular}

CBNAAT: cartridge-based nucleic acid amplification test; COVID-19: novel Coronavirus disease; RT-PCR: reverse transcriptase-polymerase chain reaction, SARS-Co-V-2: severe acute respiratory syndrome coronavirus 2, TruNat: chip-based RT-PCR test.

Rheumatology is recommended for evaluation of a suspect case. Treatment options include intravenous immunoglobulin, methylprednisolone, and aspirin (Web Fig 1). Neonates with suspected MIS should be managed at tertiary care hospitals where multidisciplinary and cardiology support is available.

\section{CONCLUSION}

The updated perinatal COVID guideline addresses the use of antenatal steroids, COVID vaccination for pregnant and lactating women, testing and treatment of COVID-19, and the multisystem inflammatory syndrome in neonates.

\section{REFERENCES}

1. Cherian S, Potdar V, Jadhav S, et al. SARS-CoV-2 spike mutations, L452R, T478K, E484Q and P681R, in the second wave of COVID-19 in Maharashtra, India. Microorganisms. 2021;9:1542.

2. Chawla D, Chirla D, Dalwai S, et al. Perinatal-Neonatal Management of COVID-19 Infection - Guidelines of the Federation of Obstetric and Gynaecological Societies of India (FOGSI), National Neonatology Forum of India (NNF), and Indian Academy of Pediatrics (IAP). Indian Pediatr. 2020;57:536-48.

3. Indian Council of Medical Research (ICMR). Advisory for COVID-19 testing during the second wave of the pandemic. Accessed My 25, 2021. Available from: https://www.icmr.gov. in/pdf/covid/strategy/Advisory_COVID_Testing_in_Second_ Wave_04052021.pdf
4. Perinatal-Neonatal Management of COVID-19- Clinical practice guidelines (Version 3.0). Accessed Aug 20, 2021. Available from: https://www.nnfi.org/assests/upload/usefull-links-pdf/ NNF_FOGSI\%20IAP_Perinatal-Neonatal_Covid_CPG_June_ 16-2021.pdf

5. Villar J, Ariff S, Gunier RB, et al. Maternal and neonatal morbidity and mortality among pregnant women with and without COVID-19 infection: The INTERCOVID Multinational Cohort Study. JAMA Pediatr. 2021;175: 817-26.

6. Mullins E, Hudak ML, Banerjee J, et al. Pregnancy and neonatal outcomes of COVID-19: coreporting of common outcomes from PAN-COVID and AAP-SONPM registries. Ultrasound Obstet Gynecol. 2021;57:573-81.

7. Allotey J, Stallings E, Bonet M, et al. for PregCOV-19 living systematic review consortium. Clinical manifestations, risk factors, and maternal and perinatal outcomes of coronavirus disease 2019 in pregnancy: living systematic review and metaanalysis. BMJ. 2020;370: m3320.

8. RECOVERY Collaborative Group, Horby P, Lim WS, et al. Dexamethasone in hospitalized patients with COVID-19. N Engl J Med. 2021;384:693-704.

9. Magala S A, Sserwanja Q, Olal E, et al. Corticosteroids use in pregnant women with COVID-19: Recommendations from available evidence. J Multidiscip Healthc. 2021;14:659-63.

10. World Health Organization. Corticosteroids for COVID-19. Accessed May 29, 2021. Available from: https://apps.who.int/ iris/rest/bitstreams/1299344/retrieve

11. More K, Chawla D, Murki S, et al. National Neonatology Forum (NNF) COVID-19 Registry Group. Outcomes of neonates born to mothers with coronavirus disease 2019 (COVID-19) National Neonatology Forum (NNF) India COVID-19 Registry. Indian Pediatr. 2021;58:525-31. 